\title{
Factors associated with diarrhea and acute respiratory infection in children under two years of age in rural Bangladesh
}

Md Barkat Ullah ${ }^{1 *}$ (D), Malay K. Mridha ${ }^{2}$, Charles D. Arnold ${ }^{1}$, Susana L. Matias ${ }^{3}$, Md Showkat A. Khan², Zakia Siddiquii, Mokbul Hossain ${ }^{2}$, Rina Rani Paul ${ }^{5}$ and Kathryn G. Dewey ${ }^{1}$

\begin{abstract}
Background: Diarrhea and acute respiratory infection (ARI) are major causes of child mortality. We aimed to identify risk factors associated with diarrhea and ARI among children under 2 years of age in rural northern Bangladesh.
\end{abstract}

Method: We collected information on diarrhea and ARI in the previous 14 days and the previous 6 months at 6,12 , 18 and 24 months of age as part of a longitudinal, cluster randomized effectiveness trial, the Rang-Din Nutrition Study which enrolled 4011 pregnant women at $\leq 20$ gestational weeks. Women and their children were followed up until 2 years postpartum. Information on household socioeconomic status, type of toilet, garbage disposal system, food insecurity, number of under-five children in the household, type of family, maternal characteristics and child characteristics was collected at baseline and/or at 6, 12, 18 and 24 months postpartum. Data on newborn health and feeding behaviors were collected within $72 \mathrm{~h}$ of delivery. Associations between potential risk factors and morbidity prevalence outcomes were assessed using logistic regression controlling for potential confounders.

Results: Out of 3664 live born children, we collected information from 3350 children at 6, 12, 18 and 24 months of age. Diarrhea in the previous 14 days, and in the previous 6 months, was associated with maternal depression score and food insecurity; diarrhea in the previous 6 months was also associated with family type (nuclear vs. joint). ARI in the previous 14 days was associated with maternal depression score, type of toilet and garbage disposal, household food insecurity and sex. Cough or nasal discharge in the past 6 months was associated with maternal depression score, type of toilet and garbage disposal, household food insecurity, sex and perceived overall physical condition of the infant after birth.

Conclusion: Maternal depression and food insecurity appear to be important risk factors for diarrhea and respiratory infection among children under 2 years of age in this setting. These findings suggest that policies and programs that include strategies to address maternal mental health and household food insecurity may contribute to improved child health.

Trial registration: The trial was registered with the US National Institutes of Health at ClinicalTrials.gov, \# NCT01715038, with registration completed October 26, 2012.

Keywords: Acute respiratory infection, Diarrhea, Child health, Child morbidity, Food insecurity, Maternal mental health

\footnotetext{
*Correspondence: mullah@ucdavis.edu

'Department of Nutrition, University of California, One Shields Ave., Davis, CA

95616, USA

Full list of author information is available at the end of the article
}

(c) The Author(s). 2019 Open Access This article is distributed under the terms of the Creative Commons Attribution 4.0 International License (http://creativecommons.org/licenses/by/4.0/), which permits unrestricted use, distribution, and reproduction in any medium, provided you give appropriate credit to the original author(s) and the source, provide a link to the Creative Commons license, and indicate if changes were made. The Creative Commons Public Domain Dedication waiver (http://creativecommons.org/publicdomain/zero/1.0/) applies to the data made available in this article, unless otherwise stated. 


\section{Introduction}

Globally pneumonia and diarrhea are major causes of child mortality, accounting for 15.5 and $8.9 \%$, respectively, of deaths among children under 5 years of age in 2015 [1]. The Millennium Development Goal (MDG) for reducing under-five mortality was not met at the global level [2], and the new goal, part of the Sustainable Development Goals, is to reduce under-five mortality to 25 per 1000 live births or less by 2030 [3]. In Bangladesh, the under-five mortality rate was 46 per 1000 live births in 2014 (Bangladesh Demographic and Health Survey 2014), and symptoms of acute respiratory infection (ARI) and diarrhea were present among 6 and 5\%, respectively, of the under five children in the 2 weeks prior to the survey interview [4].

Incidence rates of respiratory infections [5-11] and diarrhea [11-17] are highest in the first 2 years of life and are related not only to child mortality but also to impaired physical growth and development of children [18]. Although many studies have been conducted to identify the factors associated with ARI and diarrhea in lowerincome countries, most have included all children under 5 years of age, and have not focused on the first 2 years of life. Factors associated with both ARI and diarrhea among children under five include lower household Xsocioeconomic status $[5,11,13,15,19-21]$, poor sanitation $[12,15,17,20,22]$, larger family size $[6,9,12,13,17]$, living in a rural area $[11,14,17,23]$, younger mother $[7,11]$, low maternal education $[11,12,15,21,22,24]$, male child [10, 13, 15, 23], younger child [5-17], higher birth order of the child [9, 12, 22], suboptimal breastfeeding practices $[9,11,24,25]$, inadequate complementary feeding practices [20, 23, 24] and poor anthropometric status of the child [9, 11, 15, 20, 24]. Other factors associated with ARI include use of biomass fuel for cooking [5, 8, 24], low paternal education [24], and prematurity [24], and other factors associated with diarrhea include improper waste disposal [12, 17, 21, 22], improper drainage system [22, 26], unsafe drinking water $[15,26]$, maternal depression [27], improper hand washing [11, 15, 21-23] and lower birth order of the child [11].

There is little information on which of the above risk factors are most critical during the first 2 years of life. In addition, most of the above studies did not include household food insecurity or maternal mental health as potential risk factors in the analysis, even though these may be quite important in the etiology of infectious disease in young children. Food insecurity may be linked to greater risk of morbidity via inadequate nutrient intake, given the important role that several nutrients play in immune function [28-31]. Maternal mental health may affect child caregiving and thus also be related to risk of infection $[27,32]$. We used data from a large intervention trial in rural Bangladesh, the RangDin Nutrition Study (RDNS) [33] to identify risk factors associated with ARI and diarrhea among children under 2 years of age.

\section{Methods \\ Study setting}

Data for these analyses come from a longitudinal, cluster-randomized effectiveness trial of nutritional supplements for pregnant and lactating women and their children through 2 years of age, conducted in 11 rural unions (lowest administrative unit of local government of Bangladesh) of the Badarganj and Chirirbandar subdistricts in northwest Bangladesh, as described previously [33]. It was implemented within the Community Health and Development Program (CHDP) operated by a local non-government organization (LAMB). Health services normally provided by the CHDP include maternity services at a safe delivery unit (SDU) in each union, regular home visits for antenatal, postnatal and child care by village health volunteers (VHV) and community health workers $(\mathrm{CHW})$, and monthly educational sessions to promote maternal and child health. Clusters were defined as the work areas of the CHWs. Details regarding supplement composition, distribution scheme and key educational messages are provided elsewhere $[33,34]$. The study protocol was approved by the institutional review boards of University of California, Davis (UCD); icddr,b; and LAMB. We obtained verbal consent from union representatives before beginning the study, and completed randomization of clusters before seeking individual participant's written consent [33].

\section{Enrollment and data collection}

The CHWs and VHVs identified pregnant women [33], and those potentially eligible for the RDNS were contacted at home by evaluation staff. Eligibility criteria included gestational age $\leq 20$ weeks and no plans to move away during pregnancy or the following 3 years. All eligible women were invited to participate; those who consented were interviewed to collect baseline data as described elsewhere [33, 34].

Data collection was performed by 2 separate teams: the "SDU visit team," which collected clinical and anthropometric data at the SDU, and the "home visit team, " which enrolled mothers and collected baseline and follow-up data at participants' homes.

Baseline data on socioeconomic status, maternal characteristics, type of toilet, garbage disposal system, indoor air quality, number of under-five children in the household, family type and household food insecurity were collected at enrollment. For household socioeconomic status a set of 19 yes/no questions were asked about whether or not a household owned a particular item. 
These items included televisions, irrigation pumps, tables, bicycles, sewing machines, and other goods [33, 34]. We collected data on household food insecurity using the Household Food Insecurity Access Scale [35]. We assessed indoor air quality based on 5 questions about type of cooking facility, cooking location, type of fuel used for cooking, hours per day spent for cooking, and number of household members who smoked. Trained interviewers observed the type of toilet used and garbage disposal system.

Follow up during pregnancy and just after childbirth is described elsewhere [33]. At 6, 12, 18 and 24 months postpartum, mothers/caregivers were asked if their children had specific symptoms or illnesses: a) in the previous 2 weeks, and b) in the previous 6 months. Interviewers used standard procedures to help them understand the period of recall, and probed for each symptom or illness. For the 2-week recall, the symptom list included fever (any fever; high fever, defined as very hot to the touch), cough, nasal discharge fast breathing (faster than usual), difficulty in breathing, wheezing or grunting or whistling (any abnormal sound during breathing in or out), chest indrawing (not asked at 6 months interview), diarrhea (passage of abnormally loose or watery stool more than 3 times in a $24 \mathrm{~h}$ period), convulsion (shaking of hands, legs or body when ill), and lethargy/drowsiness (too weak to speak, move or play normally). If the mother/caregiver reported "yes" for any of the symptoms, she was then asked how many days in the last 2 weeks the child had that symptom. If the mother/caregiver mentioned two or more symptoms in the last 2 weeks, she was also asked which of those symptoms were present at the same time. For the 6month recall, the mother/caregiver was asked how many episodes of three common illnesses or sets of symptoms her child experienced: 1) cough or nasal discharge 2) cough or nasal discharge accompanied by fast or difficult breathing (this question was nested within the first question, so that if the answer to the first question was one or more, the second question was asked), and 3) diarrhea. Feeding history of the children was collected from their mothers/caregivers at $6,12,18$ and 24 months by $24 \mathrm{~h}$ recall. To the extent possible, data collectors were kept blind to group assignment, although those conducting home visits might have seen supplements in the home. Quality-control procedures [33] included having supervisors re-interview at least $10 \%$ of randomly selected participants.

\section{Outcome definitions}

Primary outcomes based on the 2-week recalls (at 6, 12, 18 and 24 months) are the percentage of children with any occurrence of: a) diarrhea (defined as stated above), b) acute upper respiratory infection (AURI), and c) acute lower respiratory infection (ALRI) during the previous 2 weeks. AURI is defined as caregiver report of cough and nasal discharge on the same day(s) but no difficulty in breathing, rapid breathing, wheezing/grunting/whistling, chest indrawing, convulsion or lethargy during those days. ALRI is defined as caregiver report of cough together with at least one of the following symptoms on the same day(s): difficulty in breathing, rapid breathing, wheezing/ grunting/whistling or chest indrawing. Secondary outcomes based on the 6-month recalls are the percentage of children with any occurrence of a) cough or nasal discharge, b) cough or nasal discharge accompanied by fast or difficult breathing, and c) diarrhea in the previous 6 months.

\section{Predictor variables}

The potential risk factors included in these analyses were based on data collected at various time points (Additional file 1: Table S1) on household socioeconomic status (asset index), type of toilet, garbage disposal system, food insecurity, number of under-five children in the household, type of family (nuclear or extended), maternal characteristics (education and depression), and child characteristics (sex, low birth weight $(<2500 \mathrm{~g})$, prematurity ( $<37$ weeks gestation), overall perceived physical condition of the newborn soon after birth (healthy or not healthy), stunting (length-for-age Z-score $[\mathrm{LAZ}]<-2$ ), and dietary diversity). We excluded indoor air quality from these analyses because more than $99 \%$ of households used bio-mass fuel for cooking and cooked on an open fire, yielding little variability in this potential predictor.

We used principal components analysis (PCA) to calculate a household asset index from the set of 19 yes/ no questions about whether or not a household owned a particular item; higher values represented higher socioeconomic status. Toilet facility was categorized into best (sanitary and water seal latrines), intermediate (pit latrine with slab and water seal) and worst (pit latrine without water seal, hanging/open latrine or no latrine). Garbage disposal system was categorized into better (burned or dumped in a designated place) and worse (no specific place to dump or dumped in open space or dumped in pond/river/canal). Household food insecurity was categorized into four levels of household food insecurity (severe, moderate, mild, and none) [33]. We defined maternal depression based on the top decile of maternal depression scores in the study population at each time point (baseline, 6 and 24 months postpartum) using a 10 point scale modified Bengali version of the Edinburgh Postpartum Depression Scale (EPDS) [36] screening tool. We used the top decile of maternal depression scores instead of using a standard cut-off because the percentage of women with scores above the standard cut-off was very low. At baseline, 6 months and 24 months the top decile cutoffs were > $7,>5$ and $>5$, respectively. Child minimum dietary diversity (MDD) was defined as reported consumption during 
the previous $24 \mathrm{~h}$ of foods from four or more food groups out of the seven food groups as defined by the World Health Organization for this indicator [37].

\section{Statistical analyses}

Maternal and child characteristics were examined using frequencies and percentages for categorical data and either mean and SD or median and IQR or quartiles for continuous variables. To examine the variables related to the dichotomous morbidity outcomes, we used logistic regression and all models were longitudinal, which means they included all time points of data collected for a child. To account for the cluster design of the trial and repeated measurements on the same child we used robust sandwich variance estimation with clusters as the independent unit. All models controlled for intervention group assignment and age category of data collection. If data were missing at a time point, then that time point was not included for that child. For models of morbidity outcomes based on the 2-week recalls, predictor variables were based on concurrent or the most recently collected information (Additional file 1: Table S2). The same predictor variables were used for analyzing all morbidity outcomes.

For models of morbidity outcomes based on the 6month recalls, predictor variables were based on information collected at the beginning of each 6-month period or as close to that time point as possible (Additional file 1: Table S3). We first assessed bivariate associations and used odds ratios (ORs) and descriptive statistics to understand the direction of the relationships. Then in separate models we assessed the interaction between predictor and age category to determine whether the association between predictor and outcome varied by age, and created figures to visualize significant interactions. We controlled for multiple hypothesis testing by correcting bivariate and interaction $p$-values using Benjamini-Hochberg multiple hypothesis correction [38]. Predictors significant in bivariate analyses were included in a multivariable model to assess whether they retained significance when controlling for other predictor variables. Collinearity was first assessed using a variance inflation factor cutoff of 5 and if necessary, a single predictor was selected from predictors representing the same construct.

\section{Results}

A total of 3664 live births occurred between January 15, 2012 and May 5, 2013, as described elsewhere [33]. There were 30 twin deliveries (including stillbirth) and one twin from each pair was randomly selected for analysis. The numbers of children for whom data were collected at each time point are shown in the Additional file 2: Figure S1; at 24 months of age, more than $90 \%$ of the live born children remained in the study. Socioeconomic characteristics of the mother-infant dyads who were lost to follow up were compared with those of the dyads who were included in this analysis. Dyads lost to follow-up differed in several ways including greater maternal age, lower maternal height, lower maternal education, shorter duration of gestation, more likely to be a nuclear family, lower household assets, greater food insecurity, higher percentage of preterm delivery, lower birth weight and greater likelihood of newborn stunting, compared to those who remained in the analysis (Table 1).

In this sample, less than $13.1 \%$ of the households had a flush or water seal toilet, while $74.7 \%$ had a garbage disposal system categorized as "better". At baseline 8.7, $28.9,14.3$ and $48.0 \%$ of households were categorized as having severe, moderate, mild and no food insecurity, respectively. Average family size was $\sim 4.6$, about $37.5 \%$ of the households had at least one child under 5 years of age at baseline and most (73.7\%) were nuclear families. Mean maternal age was 21.9 years, on average they attended 6.3 years in school, $39.8 \%$ of the women were nulliparous and their average gestational age at enrollment was 13 weeks. Half of the infants were male. Average birth weight was $2610 \mathrm{~g}$, prevalence of low birth weight was 29.5 , and $13.1 \%$ were born preterm. Nearly all (91.7\%) of the newborns were rated as "healthy" based on the overall condition of the baby soon after birth. The prevalence of stunting was 24.0, 28.3, 34.7 and $40.6 \%$ at $6,12,18$ and 24 months, respectively. MDD was $2.9,53.2,66.3$ and $74.4 \%$ at $6,12,18$ and 24 months, respectively.

\section{Factors associated with prevalence of diarrhea Previous 2 weeks}

The percentage of children with reported diarrhea in the previous 2 weeks was $6.8,7.8,7.5$ and $3.4 \%$ at $6,12,18$ and 24 months, respectively. Asset index, maternal education, maternal depression score in the top decile, food insecurity and family type (nuclear vs joint) were significantly associated with the prevalence of diarrhea in the previous 2 weeks in bivariate analysis, whereas type of toilet, garbage disposal system, minimum dietary diversity, number of under-five children in the household, sex of the child, low birth weight, prematurity, stunting and rating of the overall condition of the infant soon after birth were not associated with diarrhea prevalence in the previous 2 weeks (data not shown).

In multivariable analysis (Table 2, which includes only the predictors that were significantly related to at least one outcome), diarrhea was more likely among children of mothers scoring in the top decile of the depression screening tool [AOR (95\% CI), 1.58 (1.31, 1.90)] compared to those scoring lower, and among children in households with moderate [AOR (95\% CI), $1.23(1.01,1.50)]$ or severe [AOR $(95 \% \mathrm{CI}), 1.33$ (1.00, 
Table 1 Socioeconomic, maternal and child characteristics of the mother-infant dyads in the analyses, compared to those who were lost to follow up

\begin{tabular}{|c|c|c|c|}
\hline & $\begin{array}{l}\text { Not lost to follow-up } \\
\text { (Mean } \pm \text { SD) }\end{array}$ & $\begin{array}{l}\text { Lost to follow-up } \\
\text { (Mean } \pm \text { SD) }\end{array}$ & $P$-value \\
\hline Maternal characteristics & $n=3530$ & $n=481$ & \\
\hline Age, (y) & $21.9 \pm 4.9$ & $22.4 \pm 5.6$ & 0.023 \\
\hline Height (cm) & $150.6 \pm 5.4$ & $149.9 \pm 5.3$ & 0.005 \\
\hline BMI $\left(\mathrm{kg} / \mathrm{m}^{2}\right)$ & $20.0 \pm 2.7$ & $19.9 \pm 2.7$ & 0.752 \\
\hline Years of education & $6.3 \pm 3.2$ & $5.6 \pm 3.4$ & $<0.001$ \\
\hline Nulliparous, n (\%) & $1404(39.8)$ & $187(39.4)$ & 0.886 \\
\hline Maternal depression score in the top decile (\%) & 9.6 & 10.8 & 0.190 \\
\hline Gestational age at enrolment, (d) & $92.0 \pm 26.9$ & $91.2 \pm 24.4$ & 0.505 \\
\hline Gestational age at birth (wk) & $39.4 \pm 2.2$ & $37.9 \pm 3.7$ & $<0.001$ \\
\hline Type of toilet (\%) & & & 0.231 \\
\hline Best & 13.1 & 10.4 & \\
\hline Intermediate & 25.6 & 25.8 & \\
\hline Worse & 61.3 & 63.8 & \\
\hline Better garbage disposal (\%) & 74.7 & 74.2 & 0.855 \\
\hline Number of children $<5 y$ in the household & $0.43 \pm 0.60$ & $0.39 \pm 0.60$ & 0.319 \\
\hline Nuclear family (\%) & 73.7 & 79.8 & 0.007 \\
\hline Household asset index & $0.04 \pm 2.27$ & $-0.33 \pm 2.12$ & 0.003 \\
\hline Household food insecurity, n, (\%) & & & 0.039 \\
\hline Food secure & $1696(48.0)$ & $205(42.6)$ & \\
\hline Mildly food insecure & $506(14.3)$ & 75 (15.6) & \\
\hline Moderately food insecure & $1020(28.9)$ & $143(29.7)$ & \\
\hline Severely food insecure & $308(8.7)$ & $58(12.1)$ & \\
\hline Child characteristics & $n=3517$ & $n=228$ & \\
\hline Sex, male, n, (\%) & $1770(50.3)$ & $110(48.2)$ & 0.589 \\
\hline Stunting at birth (\%) & 21.0 & 54.9 & $<0.001$ \\
\hline Perceived as healthy (\%) & 91.7 & 54.2 & $<0.001$ \\
\hline Prematurity (\%) & 13.1 & 39.4 & $<0.001$ \\
\hline Birth weight (g) & $2610 \pm 400$ & $2160 \pm 600$ & $<0.001$ \\
\hline
\end{tabular}

1.75)] food insecurity compared to those in households with no food insecurity. Diarrhea was less likely among children in joint families [AOR (95\% CI), 0.72 (0.61, $0.85)$ ] compared to those in nuclear families.

\section{Previous 6 months}

The percentage of children with any occurrence of reported diarrhea in the previous 6 months was 20.1, $28.8,28.8$ and $16.9 \%$ at $6,12,18$ and 24 months, respectively. Maternal depression score and food insecurity were significantly associated with prevalence of diarrhea in the last 6 months in bivariate analysis, whereas asset index, maternal education, type of toilet, garbage disposal system, dietary diversity, number of under-five children in the household, type of family, sex of the child, low birth weight, prematurity, stunting and perceived overall condition of the infant soon after birth were not associated with diarrhea prevalence in the previous 6 months (data not shown).

In multivariable analysis (Table 3 , which includes only the predictors that were significantly related to at least one outcome), diarrhea was more likely among children of mothers scoring in the top decile of the depression screening tool [AOR (95\% CI), 1.43 (1.28, 1.60)] compared to those scoring lower, and among children in households with mild [AOR (95\% CI), 1.15 (1.02, 1.30)], moderate [AOR (95\% CI), 1.26 (1.15, 1.39)] or severe [AOR $(95 \% \mathrm{CI}), 1.47(1.22,1.77)]$ food insecurity compared to those in households with no food insecurity. 
Table 2 Association of diarrhea and respiratory infections in the previous 2 weeks with potential risk factors

\begin{tabular}{|c|c|c|c|c|c|c|}
\hline \multirow[t]{2}{*}{ Variables } & \multicolumn{2}{|c|}{ Observations with diarrhea } & \multicolumn{2}{|c|}{ Observations with ALRI } & \multicolumn{2}{|c|}{ Observations with AURI } \\
\hline & $\%$ & $\begin{array}{l}\text { AOR } \\
(95 \% \mathrm{Cl})\end{array}$ & $\%$ & $\begin{array}{l}\text { AOR } \\
(95 \% \mathrm{Cl})\end{array}$ & $\%$ & $\begin{array}{l}\text { AOR } \\
(95 \% \mathrm{Cl})\end{array}$ \\
\hline \multicolumn{7}{|c|}{ Maternal depression score in the top decile } \\
\hline Yes & 9.7 & $1.58(1.31,1.90)$ & 17.7 & $1.29(1.10,1.51)$ & 30.6 & - \\
\hline No & 6.0 & - & 12.7 & - & 30.3 & - \\
\hline \multicolumn{7}{|l|}{ Type of toilet } \\
\hline Best & 5.3 & - & 11.1 & - & 29.4 & - \\
\hline Intermediate & 6.7 & - & 16.5 & $1.31(1.10,1.56)$ & 28.4 & - \\
\hline Worst & 6.7 & - & 13.0 & $0.94(0.81,1.09)$ & 31.2 & - \\
\hline \multicolumn{7}{|l|}{ Garbage disposal } \\
\hline Best & 6.5 & - & 12.7 & - & 30.2 & - \\
\hline Worst & 5.5 & - & 16.5 & $1.30(1.13,1.49)$ & 29.8 & - \\
\hline \multicolumn{7}{|l|}{ Food insecurity } \\
\hline Food secure & 5.7 & & 11.5 & & 29.2 & \\
\hline Mild food insecurity & 7.4 & $1.17(0.92,1.50)$ & 14.5 & $1.21(1.01,1.45)$ & 29.4 & $1.01(0.89,1.14)$ \\
\hline Moderate food insecurity & 7.9 & $1.23(1.01,1.50)$ & 17.8 & $1.59(1.42,1.78)$ & 32.8 & $1.18(1.07,1.30)$ \\
\hline Severe food insecurity & 8.1 & $1.33(1.00,1.75)$ & 20.0 & $1.95(1.55,2.45)$ & 34.2 & $1.24(1.02,1.51)$ \\
\hline \multicolumn{7}{|l|}{ Family type } \\
\hline Nuclear & 6.6 & & 13.1 & & 29.9 & - \\
\hline Joint family & 5.0 & $0.72(0.61,0.85)$ & 14.1 & - & 30.9 & - \\
\hline \multicolumn{7}{|l|}{ Sex of the child } \\
\hline Male & 6.1 & - & 14.8 & - & 29.7 & - \\
\hline Female & 6.7 & - & 11.8 & $0.76(0.68,0.85)$ & 30.4 & - \\
\hline
\end{tabular}

Multivariable adjusted odds ratio and 95\% confidence interval for occurrence of diarrhea, ALRI and AURI in the previous 2 weeks before $6,12,18$ and 24 months of age. Models are longitudinal and control for time point of data collection. First category for all predictors has been considered as the reference category. Dashes signify non-significant relationships and reference categories. Only the predictors that were significantly associated with at least one outcome are shown. AORs in boldface are statistically significant at $p<0.05$; AORs not in boldface are not significant but are provided for completeness for all categories of those predictor variables

\section{Factors associated with respiratory infections} $A L R I$ in the previous 2 weeks

The percentage of children with reported ALRI in the previous 2 weeks was $17.6,15.2,11.6$ and $8.8 \%$ at 6,12 , 18 and 24 months, respectively. Maternal depression score, type of toilet, garbage disposal system, food insecurity and sex of the child were significantly associated in bivariate analyses with prevalence of ALRI, whereas asset index, maternal education, dietary diversity, type of family, number of under-five children in the household, low birth weight, prematurity, stunting and perceived overall condition of the infant soon after birth were not associated with ALRI prevalence (data not shown).

In multivariable analysis (Table 2), ALRI was more likely among children of mothers scoring in the top decile of the depression screening tool [AOR (95\% CI), 1.29 (1.10, 1.51)] compared to those scoring lower, among children in households with "intermediate" quality toilets [AOR (95\% CI), $1.31(1.10,1.56)]$ compared to those in households with "best" quality toilets, among children in households with "worse" garbage disposal systems [AOR (95\% CI), 1.30
$(1.13,1.49)]$ compared to those in households with "better" garbage disposal systems, and among children in households with mild [AOR (95\% CI), 1.21 (1.01, 1.45)], moderate [AOR $(95 \% \mathrm{CI}), 1.59(1.42,1.78)]$ or severe [AOR $(95 \% \mathrm{CI})$, $1.96(1.55,2.45)]$ food insecurity compared to those in the households with no food insecurity. ALRI was less likely among female children [AOR (95\% CI), $0.76(0.68,0.85)]$ compared to male children.

\section{AURI in the previous 2 weeks}

The percentage of children with reported AURI in the previous 2 weeks was 30.6, 30.1, 30.0 and $29.6 \%$ at 6,12 , 18 and 24 months, respectively. Only food insecurity was significantly associated with prevalence of AURI in bivariate analysis, whereas asset index, maternal education, maternal depression score, type of toilet, garbage disposal system, dietary diversity, type of family, number of under-five children in the household, sex of the child, low birth weight, prematurity, stunting and perceived overall condition of the infant soon after birth were not associated with AURI prevalence (data not shown). 
Table 3 Association of diarrhea and respiratory infections in the previous 6 months with potential risk factors

\begin{tabular}{|c|c|c|c|c|c|c|}
\hline \multirow[t]{2}{*}{ Variables } & \multicolumn{2}{|c|}{$\begin{array}{l}\text { Observations with } \\
\text { diarrhea }\end{array}$} & \multicolumn{2}{|c|}{$\begin{array}{l}\text { Observations with cough or nasal } \\
\text { discharge }\end{array}$} & \multicolumn{2}{|c|}{$\begin{array}{l}\text { Observations with cough or nasal discharge } \\
\text { accompanied with fast breathing }\end{array}$} \\
\hline & $\%$ & $\begin{array}{l}\mathrm{AOR} \\
(95 \% \mathrm{Cl}) \\
\end{array}$ & $\%$ & $\begin{array}{l}\text { AOR } \\
(95 \% \mathrm{Cl}) \\
\end{array}$ & $\%$ & $\begin{array}{l}\text { AOR } \\
(95 \% \mathrm{Cl}) \\
\end{array}$ \\
\hline \multicolumn{7}{|c|}{ Maternal depression score in the top decile } \\
\hline Yes & 31.0 & $1.43(1.28,1.60)$ & 92.0 & $1.44(1.14,1.83)$ & 28.1 & $1.38(1.18,1.62)$ \\
\hline No & 22.7 & - & 88.4 & - & 22.0 & - \\
\hline \multicolumn{7}{|l|}{ Type of toilet } \\
\hline Best & 21.4 & - & 85.4 & - & 19.1 & - \\
\hline Intermediate & 23.9 & - & 90.4 & $1.26(1.04,1.53)$ & 26.0 & $1.18(1.02,1.36)$ \\
\hline Worst & 24.4 & - & 89.8 & $\begin{array}{l}1.10 \\
(0.95,1.27)\end{array}$ & 22.9 & $\begin{array}{l}1.00 \\
(0.88,1.14)\end{array}$ \\
\hline \multicolumn{7}{|l|}{ Garbage disposal } \\
\hline Best & 23.6 & - & 88.6 & - & 22.0 & - \\
\hline Worst & 23.8 & - & 90.0 & - & 26.0 & $1.17(1.03,1.33)$ \\
\hline \multicolumn{7}{|l|}{ Food insecurity } \\
\hline Food secure & 21.6 & & 87.0 & & 19.4 & \\
\hline Mild food insecurity & 26.7 & $1.15(1.02,1.30)$ & 92.8 & $1.43(1.14,1.79)$ & 28.8 & $1.11(0.96,1.28)$ \\
\hline Moderate food insecurity & 28.1 & $1.26(1.15,1.39)$ & 92.8 & $1.31(1.11,1.54)$ & 29.0 & $1.33(1.21,1.45)$ \\
\hline Severe food insecurity & 31.0 & $1.47(1.22,1.77)$ & 93.3 & $1.68(1.17,2.40)$ & 33.5 & $1.62(1.33,1.98)$ \\
\hline \multicolumn{7}{|l|}{ Sex of the child } \\
\hline Male & 24.3 & - & 89.7 & - & 24.4 & \\
\hline Female & 23.0 & - & 87.9 & $0.82(0.72,0.94)$ & 20.9 & $0.81(0.73,0.89)$ \\
\hline \multicolumn{7}{|c|}{ Maternal perception of infant condition at birth } \\
\hline Healthy & 23.5 & - & 88.6 & - & 22.5 & - \\
\hline Not healthy & 25.4 & - & 91.9 & $1.49(1.16,1.91)$ & 25.0 & - \\
\hline
\end{tabular}

Multivariable adjusted odds ratio and $95 \%$ confidence interval for occurrence of any episode of diarrhea, cough or nasal discharge, and cough or nasal discharge accompanied with fast breathing or difficulty in breathing in the last 6 months before $6,12,18$ and 24 months of age. Models are longitudinal and control for time point of data collection. First category for all predictors has been considered as the reference category. Dashes signify non-significant relationships and reference categories. Only the predictors that were significantly associated with at least one outcome are shown. AORs in boldface are statistically significant at $p<0.05$; AORs not in boldface are not significant but are provided for completeness for all categories of those predictor variables

In multivariable analysis (Table 2), AURI was more likely among children in households with moderate [AOR $(95 \%$ CI), $1.18(1.07,1.30)$ ] or severe [AOR (95\% CI), $1.24(1.02,1.51)]$ food insecurity compared to those in households with no food insecurity.

\section{Cough or nasal discharge in the previous 6 months}

The percentage of children with cough or nasal discharge in the previous 6 months was 97.8, 92.9, 84.4 and $80.0 \%$ at $6,12,18$ and 24 months, respectively. Maternal depression score, type of toilet, food insecurity, sex of the child, prematurity and perceived overall condition of the infant soon after birth were significantly associated with prevalence of cough or nasal discharge in the previous 6 months in bivariate analysis, whereas asset index, maternal education, garbage disposal system, dietary diversity, type of family, number of under-five children in the household, low birth weight and stunting were not associated with cough or nasal discharge prevalence (data not shown).

In multivariable analysis (Table 3), cough or nasal discharge was more likely among children of mothers scoring in the top decile of the depression screening tool [AOR $(95 \% \mathrm{CI}), 1.44(1.14,1.83)]$ compared to those scoring lower, among children in households with "intermediate" quality toilets [AOR (95\% CI), 1.26 $(1.04,1.53)]$ compared to those in households with "best" quality toilets, among children in households with mild [AOR $(95 \% \mathrm{CI}), 1.43(1.14,1.79)$ ], moderate [AOR $(95 \% \mathrm{CI}), 1.31(1.11,1.54)$ ] or severe [AOR (95\% CI), $1.68(1.17,2.40)]$ food insecurity compared to those in households with no food insecurity, and among children rated as "not healthy" soon after birth [AOR (95\% CI), $1.49(1.16,1.91)]$ compared to those rated as "healthy". Cough or nasal discharge was less likely among female children [AOR (95\% CI), 0.82 $(0.72,0.94)]$ compared to male children. 


\section{Cough or nasal discharge accompanied by fast or difficult breathing in the previous 6 months}

The percentage of children with cough or nasal discharge accompanied by fast or difficult breathing in the previous 6 months was 38.6, 24.0, 15.6 and $12.3 \%$ at 6 , 12, 18 and 24 months, respectively. Maternal depression score, type of toilet, garbage disposal system, food insecurity and sex of the child were significantly associated with prevalence of this outcome in bivariate analysis, whereas asset index, maternal education, dietary diversity, type of family, number of under-five children in the household, low birth weight, prematurity, stunting and perceived overall condition of the infant soon after birth were not associated with this outcome (data not shown).

In multivariable analysis (Table 3), cough or nasal discharge accompanied by fast or difficult breathing was more likely among children of mothers scoring in the top decile of the maternal depression screening tool [AOR (95\% CI), $1.38(1.18,1.62)]$ compared to those scoring lower, among children in households with "intermediate" quality toilets [AOR $(95 \% \mathrm{CI}), 1.18(1.02,1.36)]$ compared to those in households with "best" quality toilets, among children in households with better garbage disposal systems (compared to worse) [AOR (95\% CI), $1.17(1.03,1.33)]$, and among children in households with moderate [AOR $(95 \% \mathrm{CI}), 1.33(1.21,1.45)]$ or severe [AOR (95\% CI), $1.62(1.33,1.98)]$ food insecurity compared to those in households with no food insecurity. Cough or common cold accompanied by fast or difficult breathing was less likely among female children [AOR $(95 \% \mathrm{CI}), 0.81(0.73,0.89)]$ compared to male children.

\section{Discussion}

This study aimed to identify risk factors associated with diarrhea and respiratory infection in children under 2 years of age in rural Bangladesh. Controlling for other factors, we found that scoring in the top decile on the maternal depression screening tool and household food insecurity were associated with higher likelihood of reported diarrhea and respiratory infections in both short (previous 2 weeks) and long term (previous 6 months) recall periods. In addition, male children were more likely than female children to experience respiratory infections, children living in households with better quality toilets or garbage disposal systems had lower prevalence of respiratory infections, and those living in joint (vs. nuclear) families had lower prevalence of diarrhea. Other potential risk factors, such as number of children under five in the household, low birth weight, stunting and dietary diversity, were not associated with these morbidity outcomes in either bivariate or multivariable analyses in this population.
The positive association between a higher maternal depression score and reported diarrhea is consistent with findings from another cohort study in Pakistan, in which a greater number of diarrheal episodes were reported from birth to 12 months among infants of mothers who were identified as having prenatal clinical depression compared to those of psychologically well mothers [RR $(95 \% \mathrm{CI}), 2.4(1.7 ; 3.3)]$ [27]. A possible explanation for this relationship is compromised maternal ability to provide proper care for her child. In the Pakistan study, infants of the mothers who were clinically depressed during late pregnancy were less likely to be fully immunized at 12 months [27]. We also found a positive association between higher maternal depression score and respiratory infection, whereas this relationship was not observed in the Pakistan study [27]. Other investigators have demonstrated that depressed mothers tend to have negative views about their parenting ability [32] and they respond more slowly to their children [39], which could negatively influence the physical wellbeing of their children. In Sweden, the rate of hospital admission and mortality was higher among preschool children of mentally ill mothers [40]. In our study, recall bias or reverse causality cannot be excluded, e.g. a depressed mother may be more likely to view her child as sickly and be more likely to recall illness episodes.

We were unable to locate other studies that have examined the relationship between household food insecurity and diarrhea or respiratory infections. However, food insecurity has been associated with poor health outcomes of children in low income families in the U.S. [41]. Food insecurity may reduce intake of nutrients that play a role in immune function [28-31, 42-44], which could explain the associations we observed between food insecurity and diarrheal and respiratory infection. More surprising was our finding that children living in joint families had less reported diarrhea in the previous 2 weeks compared to those living in nuclear families. Other studies have shown that children in larger families are more vulnerable to diarrhea $[12,13,17]$, which may be related to quality of care and hygiene. It is possible that the joint families in our study area included more adult caregivers, compared to nuclear families, which might have enhanced the quality of care.

Our finding of greater reported prevalence of respiratory infections among boys than girls is consistent with a case-control study in Thailand [10], a cohort study in Bangladesh [45], and a systematic review of studies on hospital admission for severe acute lower respiratory infection among children under five [46]. Higher risk of infection in male children could be related to stress related thymic atrophy in male but not female infants, a phenomenon found in a study in Bangladesh [47], as smaller thymic size is associated with greater risk of 
infection [48]. Another possibility is that the suppression of immune response by testosterone $[49,50]$ could play a role, as a peak in sex hormones is observed during infancy, often referred as mini puberty [50]. The observed association is consistent with the well-known higher infant mortality rate among males compared to females [51-53]. The prevalences of all three of the morbidity outcomes based on 6-month recalls were slightly higher among the children who were rated "not healthy" soon after birth, but only the difference in prevalence of AURI was statistically significant. This suggests that the overall perceived condition of the newborn may have implications for subsequent health outcomes. Further research is needed to identify ways to reduce the risk of infection in infants who are perceived as more vulnerable.

We did not find any relationship of low birth weight or stunting at the beginning of each age interval with subsequent diarrhea or respiratory infection. A cross-sectional study of children under five in northern Bangladesh also found no relationship between stunting and respiratory infection [6]. However, low birth weight was associated with greater risk of respiratory infection among infants in a prospective cohort study in Turkey [24] and among children under five in developing countries in a 1991 review on the epidemiology of ARI [9]. It is possible that widespread access to primary health care in our study area reduced potential disparities in vulnerability of children to the types of infections reported herein.

Strengths of this study include the following: 1) large sample size; 2) all data including morbidity and anthropometric data were collected by a well-trained and standardized team; 3) newborn data were collected within $72 \mathrm{~h}$ of birth; and 4) there was a low rate of loss to follow-up at all four time points. The key limitations are that all of the morbidity outcomes were based on maternal or caregiver recall of symptoms, with a recall period of 2 weeks for some of the outcomes and 6 months for others. Other limitations are that a) information for some predictors was not available at all time points, b) generalizability of our findings is limited due to greater loss to follow-up of infants who were born preterm or with low birth weight and differences in maternal and child characteristics of this sample of children compared to those of the original study sample enrolled, c) the definition of diarrhea in our study was more restrictive than that of other studies, i.e., $>3$ (rather than $>3$ ) abnormally loose or watery stools in a $24 \mathrm{~h}$ period, and $\mathrm{d}$ ) the use of a non-standard definition for maternal depression because the percentage of women with scores above the standard cut-off was very low.

\section{Conclusion}

We conclude that a higher maternal depression score and food insecurity appear to be important risk factors for diarrhea and respiratory infection among children under 2 years of age in this setting. These findings suggest that policies and programs that include strategies to address maternal mental health and household food insecurity may contribute to improved child health. Interventions based on the principles of cognitive behavior therapy, which can be delivered by primary health workers as demonstrated in Pakistan [54], may be feasible options to tackle the burden of maternal depression in this population. Experience-based household food security scales could be used to identify households with food insecurity and target them for interventions such as food rations, food for work, or conditional cash transfer programs. Evaluations of such interventions should include child health among the outcomes assessed when documenting effectiveness and cost-effectiveness.

\section{Supplementary information}

Supplementary information accompanies this paper at https://doi.org/10 1186/s12887-019-1738-6.

Additional file 1: Table S1. Time points of data collection for predictor variables. Table S2. Predictor variables used at each time point in the analyses of associations with the morbidity outcomes for the previous 2 weeks. Table S3. Predictor variables used at each time point in the analyses of associations with the morbidity outcomes for the previous 6 months.

Additional file 2: Figure S1. Study flow chart. '366 gestational age > 140 days; 22 planned to leave the study site; 8 refused to consent and 3 husbands refused to consent. ${ }^{2}$ Most of these deaths occurred at $<14 \mathrm{~d}$ postpartum: 14 IFA-Control, 15 IFA-MNP, 15 IFA-LNS, and 17 LNS-LNS. IFAControl, women received iron and folic acid supplement during pregnancy and the first 3 months postpartum and children did not receive supplements; IFA-LNS, women received iron and folic acid during pregnancy and the first 3 months postpartum and children received lipid-based nutrient supplements from 6 to 24 months of age; IFA-MNP, women received iron and folic acid during pregnancy and the first 3 months postpartum and children received micronutrient powder from 6 to 24 months of age; LNS LNS, women and children received lipid-based nutrient supplements. "No show" refers to participants for whom data collection was not completed at that time point, primarily due to travel out of the study area or refusal because of illness or other reasons.

\section{Abbreviations \\ ALRI: Acute lower respiratory infection; ARI: Acute respiratory infection; AURl: Acute upper respiratory infection; CHDP: Community Health and Development Program; CHW: Community health worker; EPDS: Edinburgh Postpartum depression scale; FANTA: Food and Nutrition Technical Assistance project; IFA: Iron and folic acid; LAMB: Lutheran Aid for Medicine in Bangladesh (a non-government organization in DinajpurBangladesh); LNS: Lipid-based nutrient supplement; LNS-C: Lipid-based nutrient supplement for children; LNS-PL: Lipid-based nutrient supplement for pregnant and lactating women; MDD: Minimum dietary diversity; MNP: Micronutrient powder; PCA: Principal component analysis; RDNS: Rang- Din Nutrition Study; SDU: Safe delivery unit; UCD: University of California, Davis; VHV: Village health volunteer}

\section{Acknowledgements}

We thank Zeina Maalouf-Manasseh, Camila Chaparro and Megan Deitchler from FANTA; Helal Uddin Ahmed from National Institute of Mental Health, Bangladesh; Sohrab Hussain, Laura Reichenbach, Sushil Kanta Dasgupta, Ahmedul Hasan Khan, Atikul Islam Shah, Jyotish Chadra Mallik, Swapan Kumar Chanda, Preyanka Nath, Rubhana Raqib, Md. Rabiul Islam, AEM Motiur Rahman, Md. Nurunnabi Ashakhy, Golam Sarwar and other research team members and collaborators at icddr,b; Stacy Saha, Louise Tina Day, Swapan 
Pahan, Altaf Hossain, Shafiul Alam, Pronoy Ganguly, and other collaborators from LAMB; Stephen Vosti, Kassandra Harding, Janet Peerson, Christine Stewart and Rebecca Young from UC Davis, and Joseph Cummins from UC Riverside, for their technical input and support during the implementation of the study. We are thankful to the study participants. Our research intervention was incorporated into the community heath and development program of LAMB, which was supported by Plan-Bangladesh in 6 of the 11 study unions. We also thank Nutriset S.A.S. for the preparation of the LNS supplements for this trial, and Hudson Pharmaceuticals Ltd. for preparation of the IFA tablets.

\section{Authors' contributions}

All authors contributed to the design or implementation of the study and approved the final manuscript as submitted. KGD was the principal investigator for the overall project. MBU supervised data collection, quality control and data management, and wrote the first draft of this manuscript. MKM was the local principal investigator at icddr,b and supervised all study activities in Bangladesh. SLM was a co-investigator involved in study design and implementation. CDA carried out data analysis. MSAK, ZS, MH and RRP contributed to study protocols and supervised data collection and quality control at the study site. As corresponding author, MBU states that he had full access to all data and has the final responsibility to submit for publication. All authors read and approved the final version of the manuscript.

\section{Funding}

Office of Health, Infectious Diseases, and Nutrition, Bureau for Global Health, US Agency for International Development under terms of Cooperative Agreement No. AID-OAA-A-12-00005, through the Food and Nutrition Technical Assistance (FANTA) III Project, managed by FHI 360. The findings and conclusions contained within the article are those of the authors and do not necessarily reflect positions or policies of the USAID or of the United States Government. The corresponding author had full access to all the data in the study and had final responsibility for the decision to submit for publication.

\section{Availability of data and materials}

The datasets generated and/or analyzed during the current study are not yet publicly available but are available from the corresponding author on reasonable request.

\section{Ethics approval and consent to participate}

The study protocol was approved by the institutional review boards of University of California, Davis; International Center for Diarrheal Disease Research, Bangladesh (icddr,b); and LAMB Hospital, Bangladesh. The study was registered at ClinicalTrials.gov [NCT01715038]. We obtained community consent from the union representatives before beginning the study, and completed randomization of clusters before seeking informed written consent from the participants.

\section{Consent for publication}

Not applicable

\section{Competing interests}

The authors declare that they have no competing interests.

\section{Author details}

${ }^{1}$ Department of Nutrition, University of California, One Shields Ave., Davis, CA 95616, USA. ${ }^{2}$ Center for Non-communicable Disease and Nutrition, James $P$ Grant School of Public Health, BRAC University, Dhaka, Bangladesh. ${ }^{3}$ Department of Nutritional Sciences and Toxicology, University of California, 225 Morgan Hall, Berkeley, CA 94720, USA. ${ }^{4}$ Health System and Population Studies Division, ICDDR,B, Dhaka, Bangladesh. ${ }^{5}$ Care Bangladesh, Dhaka, Bangladesh.

\section{Received: 10 December 2018 Accepted: 20 September 2019} Published online: 27 October 2019

\section{References}

1. Liu L, Oza S, Hogan D, Chu Y, Perin J, Zhu J, et al. Global, regional, and national causes of under-5 mortality in 2000-15: an updated systematic analysis with implications for the Sustainable Development Goals. The Lancet. 2016;388(10063):3027-35.
2. You D, Hug L, Ejdemyr S, Idele P, Hogan D, Mathers C, et al. Global, regional, and national levels and trends in under-5 mortality between 1990 and 2015, with scenario-based projections to 2030: a systematic analysis by the UN Inter-agency Group for Child Mortality Estimation. The Lancet. 2015;386(10010):2275-86.

3. United Nations Sustainable Development Goals. Accessed 10 Aug 2018.

4. Research NloP. Training - NIPORT/Bangladesh, Mitra, Associates, ICF International. Bangladesh Demographic and Health Survey 2014. Dhaka: NIPORT, Mitra and Associates, and ICF International; 2016.

5. Kamal MM, Hasan MM, Davey R. Determinants of childhood morbidity in Bangladesh: evidence from the demographic and health survey 2011. BMJ Open. 2015;5(10):e007538.

6. Nasanen-Gilmore S, Saha S, Rasul I, Rousham EK. Household environment and behavioral determinants of respiratory tract infection in infants and young children in northern Bangladesh. Am J Hum Biol. 2015;27(6):851-8.

7. Selwyn B. The epidemiology of acute respiratory tract infection in young children: comparison of findings from several developing countries. Rev Infect Dis. 1990;12(Supplement_8):S870-S88.

8. Smith KR, Samet JM, Romieu I, Bruce N. Indoor air pollution in developing countries and acute lower respiratory infections in children. Thorax. 2000; 55(6):518-32.

9. Berman S. Epidemiology of acute respiratory infections in children of developing countries. Rev Infect Dis. 1991;13(Supplement_6):S454-S62.

10. Hasan R, Rhodes J, Thamthitiwat S, Olsen SJ, Prapasiri P, Naorat S, et al. Incidence and etiology of acute lower respiratory tract infections in hospitalized children younger than 5 years in rural Thailand. Pediatr Infect Dis J. 2014;33(2):e45.

11. Bbaale E. Determinants of diarrhoea and acute respiratory infection among under-fives in Uganda. The Australasian medical J. 2011;4(7):400.

12. Mihrete TS, Alemie GA, Teferra AS. Determinants of childhood diarrhea among underfive children in Benishangul Gumuz Regional State, North West Ethiopia. BMC Pediatr. 2014;14(1):102.

13. Siziya S, Muula A, Rudatsikira E. Correlates of diarrhoea among children below the age of 5 years in Sudan. Afr Health Sci. 2013;13(2):376-83.

14. Lee H-Y, Huy NV, Choi S. Determinants of early childhood morbidity and proper treatment responses in Vietnam: results from the Multiple Indicator Cluster Surveys, 2000-2011. Glob Health Action. 2016;9(1):29304.

15. Budhathoki SS, Bhattachan M, Yadav AK, Upadhyaya P, Pokharel PK. Eco-social and behavioural determinants of diarrhoea in under-five children of Nepal: a framework analysis of the existing literature. Trop Med Health. 2016;44(1):7.

16. Oni GA, Schumann DA, Oke EA. Diarrhoeal disease morbidity, risk factors and treatments in a low socioeconomic area of Ilorin, Kwara state, Nigeria. J Diarrhoeal Dis Res. 1991:250-7.

17. Mengistie $B$, Berhane $Y$, Worku A. Prevalence of diarrhea and associated risk factors among children under-five years of age in eastern Ethiopia: a crosssectional study. Open J Prev Med. 2013;3(07):446.

18. Dewey KG, Mayers DR. Early child growth: how do nutrition and infection interact? Matern Child Nutr. 2011;7(s3):129-42.

19. Adesanya OA, Chiao C. Environmental risks associated with symptoms of acute respiratory infection among preschool children in North-Western and SouthSouthern Nigeria communities. Int J Environ Res Public Health. 2017;14(11):1396.

20. Avachat SS, Phalke VD, Phalke DB, Aarif SM, Kalakoti P. A cross-sectional study of socio-demographic determinants of recurrent diarrhoea among children under five of rural area of Western Maharashtra, India. The Australasian Medical J. 2011;4(2):72.

21. Gebru T, Taha M, Kassahun W. Risk factors of diarrhoeal disease in underfive children among health extension model and non-model families in Sheko district rural community, Southwest Ethiopia: comparative crosssectional study. BMC Public Health. 2014;14(1):395.

22. Hashi A, Kumie A, Gasana J. Prevalence of diarrhoea and associated factors among under-five children in Jigjiga District, Somali Region, Eastern Ethiopia. Open J Prev Med. 2016;6(10):233-46.

23. Anteneh ZA, Andargie $K$, Tarekegn M. Prevalence and determinants of acute diarrhea among children younger than five years old in Jabithennan District, Northwest Ethiopia, 2014. BMC Public Health. 2017;17(1):99.

24. Etiler N, Velipasaoglu S, Aktekin M. Incidence of acute respiratory infections and the relationship with some factors in infancy in Antalya, Turkey. Pediatrics Int. 2002;44(1):64-9.

25. Amugsi DA, Aborigo RA, Oduro AR, Asoala V, Awine T, Amenga-Etego L. Socio-demographic and environmental determinants of infectious disease morbidity in children under 5 years in Ghana. Glob Health Action. 2015;8(1):29349. 
26. Karki T, Srivanichakorn S, Chompikul J, et al. Factors related to the occurrence of diarrheal disease among under-five children in Lalitpur district of Nepal. Journal of Public Health and Development. 2010;8(3)237-51.

27. Rahman A, Lovel H, Bunn J, labal Z, Harrington R. Mothers' mental health and infant growth: a case-control study from Rawalpindi, Pakistan. Child: Care, Health and Dev. 2004;30(1):21-7.

28. Mora JR, Iwata M, von Andrian UH. Vitamin effects on the immune system: vitamins A and D take centre stage. Nat Rev Immunol. 2008:8(9):685-98.

29. Wintergerst ES, Maggini S, Hornig DH. Contribution of selected vitamins and trace elements to immune function. Ann Nutr Metab. 2007;51(4):301-23.

30. Cherayil BJ. The role of iron in the immune response to bacterial infection. Immunol Res. 2011;50(1):1-9.

31. Bikle DD. Vitamin D regulation of immune function. Vitam Horm. 2010;86:1-21.

32. Goodman SH, Sewell DR, Cooley EL, Leavitt N. Assessing levels of adaptive functioning: the role functioning scale. Community Ment Health J. 1993; 29(2):119-31.

33. Mridha MK, Matias SL, Chaparro CM, Paul RR, Hussain S, Vosti SA, et al. Lipidbased nutrient supplements for pregnant women reduce newborn stunting in a cluster-randomized controlled effectiveness trial in Bangladesh. The American Journal of Clinical Nutrition. 2016;103(1):236-49.

34. Dewey K, Mridha M, Matias S, Cummins J, Peerson J, Arnold C, et al. Effectiveness of a lipid-based nutrient supplement (LNS) intervention on pregnancy and birth outcomes in Bangladesh. 2016.

35. Swindale A, Bilinsky P. Household food insecurity access scale (HFIAS) for measurement of household food access: indicator guide (v. 3). Washington, DC: Food and Nutrition Technical Assistance Project, Academy for Educational Development; 2007.

36. Cox JL, Holden JM, Sagovsky R. Detection of postnatal depression: development of the 10-item Edinburgh Postnatal Depression Scale. The British Journal of Psychiatry. 1987;150(6):782-6.

37. World Health Organization. Indicators for assessing infant and young child feeding practices: part 2: measurement. 2010.

38. Streiner DL. Best (but oft-forgotten) practices: the multiple problems of multiplicity-whether and how to correct for many statistical tests. The American Journal of Clinical Nutrition. 2015;102(4):721-8.

39. Livingood AB, Daen $P$, Smith BD. The depressed mother as a source of stimulation for her infant. J Clin Psychol. 1983;39(3):369-75.

40. Bågedahl-Strindeund $M$, Tunell $R$, Nilsson B. Children of mentally ill mothers: mortality and utilization of paediatric health services. Acta Paediatr. 1988; 77(2):242-50.

41. Cook JT, Frank DA, Berkowitz C, Black MM, Casey PH, Cutts DB, et al. Food insecurity is associated with adverse health outcomes among human infants and toddlers. J Nutr. 2004;134(6):1432-8.

42. Rink L. Zinc and the immune system. Proc Nutr Soc. 2000;59(04):541-52.

43. Shankar AH, Prasad AS. Zinc and immune function: the biological basis of altered resistance to infection. The American Journal of Clinical Nutrition. 1998;68(2):447S-63S

44. Calder PC. The relationship between the fatty acid composition of immune cells and their function. Prostaglandins Leukot Essent Fat Acids. 2008;79(3):101-8.

45. Baqui AH, Rahman M, Zaman K, El Arifeen S, Chowdhury HR, Begum N, et al. A population-based study of hospital admission incidence rate and bacterial aetiology of acute lower respiratory infections in children aged less than five years in Bangladesh. Journal Health Popul Nutr. 2007;25(2):179.

46. Nair H, Simões EA, Rudan I, Gessner BD, Azziz-Baumgartner E, Zhang JSF, et al. Global and regional burden of hospital admissions for severe acute lower respiratory infections in young children in 2010: a systematic analysis. The Lancet. 2013;381(9875):1380-90.

47. Huda MN, Ahmad SM, Alam MJ, Khanam A, Afsar MNA, Wagatsuma Y, et al. Infant cortisol stress-response is associated with thymic function and vaccine response. Stress. 2019;22(1):36-43.

48. Collinson A, Moore S, Cole T, Prentice A. Birth season and environmental influences on patterns of thymic growth in rural Gambian infants. Acta Paediatr. 2003:92(9):1014-20.

49. Trigunaite A, Dimo J, Jørgensen TN. Suppressive effects of androgens on the immune system. Cell Immunol. 2015;294(2):87-94.

50. Muenchhoff M, Goulder PJ. Sex differences in pediatric infectious diseases. J Infect Dis. 2014;209(suppl_3):S120-S6.

51. Fuse K, Crenshaw EM. Gender imbalance in infant mortality: a cross-national study of social structure and female infanticide. Social Science \& Medicine. 2006;62(2):360-74
52. Mathews TJ, MacDorman MF. Infant mortality statistics from the 2010 period linked birth/infant death data set. Natl Vital Stat Rep. 2013;62(8):1-26.

53. Garenne M. Sex differences in health indicators among children in African DHS surveys. Journal of Biosocial Science. 2003;35(4):601-14.

54. Rahman A, Malik A, Sikander S, Roberts C, Creed F. Cognitive behaviour therapy-based intervention by community health workers for mothers with depression and their infants in rural Pakistan: a cluster-randomised controlled trial. The Lancet. 2008;372(9642):902-9.

\section{Publisher's Note}

Springer Nature remains neutral with regard to jurisdictional claims in published maps and institutional affiliations.
Ready to submit your research? Choose BMC and benefit from:

- fast, convenient online submission

- thorough peer review by experienced researchers in your field

- rapid publication on acceptance

- support for research data, including large and complex data types

- gold Open Access which fosters wider collaboration and increased citations

- maximum visibility for your research: over $100 \mathrm{M}$ website views per year

At BMC, research is always in progress.

Learn more biomedcentral.com/submissions 